\title{
RESPON TANAMAN CABAI RAWIT (Capsicum frutescens L.) TERHADAP APLIKASI Trichoderma sp. PADA BEBERAPA MEDIA TANAM
}

\section{RESPONSE OF HOT CHILI PLANT (Capsicum frutescens L.) TO THE APPLICATION OF Trichoderma sp. ON SOME PLANTING MEDIA}

\author{
Tri Kurniastuti ${ }^{1)}$, Palupi Puspitorini ${ }^{1)}$, Rike Febrin $\mathbf{P}^{1)}$ \\ ${ }^{1)}$ Progam Studi Agroteknologi, Fakultas Pertanian, Universitas Islam Balitar \\ Email: kurniastuti5@gmail.com
}

\begin{abstract}
ABSTRAK
Tujuan penelitian ini untuk mengetahui interaksi antara kombinasi media tanam dan dosis Trichoderma sp. cair terhadap pertumbuhan dan produksi tanaman cabai rawi. Rancangan yang digunakan Rancangan Acak Kelompok (RAK) Faktorial yang terdapat 2 faktor dan 3 ulangan. Faktor pertama adalah kombinasi media tanam dengan 3 level yaitu $\mathrm{M} 1=$ tanah; $\mathrm{M} 2=$ tanah : arang sekam (1:1); dan $\mathrm{M} 3=$ tanah : arang sekam : pupuk kandang (1:1:1). Faktor kedua yaitu dosis Trichoderma $s p$. cair dengan 3 level yaitu $\mathrm{T} 1=5 \mathrm{ml}$ per tanaman, $\mathrm{T} 2=10$ $\mathrm{ml} /$ tanaman, dan $\mathrm{T} 3=15 \mathrm{ml} / \mathrm{tanaman}$. Variabel yang diamati meliputi tinggi tanaman, diameter batang, total jumlah buah, dan total bobot buah. Data dianalisis menggunakan analisis ragam (Uji $F$ ) dan tes lebih lanjut dengan uji duncan (DMRT) taraf 5\%. Hasil penelitian menunjukkan bahwa: terdapat interaksi yang sangat nyata pada kombinasi media tanam tanah, arang sekam, pupuk kandang dan pemberian Trichoderma sp. cair, kombinasi terbaik yaitu perlakuan media tanam tanah, arang sekam, pupuk kandang yang ditambahkan larutan Trichoderma $s p$. cair $10 \mathrm{ml}$ (M3T2) pada variabel tinggi tanaman dan diameter batang pada umur 14, 28, 42, 56, dan 70 HST, kombinasi terbaik yaitu perlakuan media tanam tanah, arang sekam, pupuk kandang yang ditambahkan larutan Trichoderma sp. cair $10 \mathrm{ml}$ (M3T2) pada variabel total jumlah buah pertanaman sebesar 98,98 buah dan total bobot buah peranaman sebesar 104,31 gram.
\end{abstract}

Kata Kunci: cabai rawit, kombinasi media tanam, Trichoderma sp. cair

\begin{abstract}
The aim of the research was to determine 1. interaction of the different planting media and the dose of Trichoderma sp. to the growth and yield of ot chili plants, 2. the effect of planting media to the growth and yield of hot chili plants production, 3) the effect of Trichoderma sp. to growth and yield of hot chili plant production. The design used was a Factorial Randomized Block Design (RBD) which contained 2 factors and was repeated 3 times. The first factor are the combination of planting media with 3 levels, namely soil, soil : husk charcoal (1:1), soil : husk charcoal : manure (1:1:1). The second factor are dosage of Trichoderma sp. solution. with 3 levels namely Trichoderma sp. $5 \mathrm{ml}$ per polybag of plant, Trichoderma sp. $10 \mathrm{ml} /$ polybag of plant, Trichoderma sp. $15 \mathrm{ml} /$ polybag of plant. Variables observed included plant height, stem diameter, total number of fruits, and total fruit weight. Data were analyzed using analysis of variance ( $F$ test) and further tests with duncan test (DMRT) level of 5\%. The results showed that: there is a very real interaction in the combination of soil
\end{abstract}


planting media, husk charcoal, manure and Trichoderma sp. liquid, the best combination is the treatment of soil planting media, husk charcoal, manure added with Trichoderma sp. $10 \mathrm{ml}$ liquid (M3T2) at variable plant height and stem diameter at the ages of 14, 28, 42, 56, and 70 DAP (Day After Planting). The best combination was the treatment of soil planting media, husk charcoal, manure added with Trichoderma sp. $10 \mathrm{ml} /$ polybag of plant (M3T2) in variable of the number of fruits total was 98.98 and the total fruit weight was 104.31 grams.

Keywords: hot chili; growing media; liquid Trichoderma sp.

\section{PENDAHULUAN}

Cabai rawit (Capsicum frutencens L.) merupakan tanaman dari anggota genus Capsicum. Cabai rawit adalah salah satu jenis tanaman hortikultura yang penting dan dibudidayakan secara komersial di Indonesia. Cabai rawit termasuk tanaman berumur pendek atau tanaman semusim dan dapat tumbuh baik di dataran tinggi maupun rendah (Kusumawati, et al., 2016). Cabai rawit digunakan sebagai bumbu sayuran, bumbu masak, acar dan asinan. Cabai rawit mengandung capsaicin, kapsantin, karotenoid, alkaloid asiri, resin, minyak atsiri, vitamin A, dan Vitamin C. Capsaisin memberikan rasa pedas dan berkhasiat untuk melancarkan aliran darah serta pemati rasa kulit. Biji cabai mengandung solanine, solamidine, solamargine, solasodine, solasomine, dan steroid saponin (kapsisidin). Kapsisidin berkhasiat sebagai antibiotik (Ajak, et al., 2016).

Kendala yang banyak dirasakan petani cabai rawit di Indonesia adalah rendahnya hasil panen. Penanaman tanaman cabai rawit memerlukan lahan yang luas, tetapi lahan pertanian semakin sempit dan harus berkompetisi dengan tanaman pangan lainnya. Salah satu cara yang dapat dilakukan agar kebutuhan cabai dapat terpenuhi yaitu dengan menanam cabai dalam polybag (Kusumawati, et al., 2016).

Hasil produksi cabai dalam polybag dapat berhasil dengan memperhatikan komposisi media tanamnya. Media tanam berfungsi sebagai tempat melekatnya akar juga sebagai penyedia hara bagi tanaman. Media tanam yang baik harus memiliki sifat fisik seperti lembab, berpori, drainase baik. Komposisi 
media tanam yang baik mengandung bahan organik seperti kompos, pupuk kandang atau bahan organik lain. Media tanam yang baik akan mendorong keberhasilan pertumbuhan tanaman, yang selanjutnya juga sangat berpengaruh terhadap produksi tanaman cabai. Menurut penelitian Kusumawati (2016), komposisi media tanam tanah + kompos dapat meningkatkan hasil bobot segar sebesar $45,25 \%$ dibandingkan dengan perlakuan media tanah saja. Penggunaan media tanam yang sesuai untuk tanaman akan berpengaruh pada pertumbuhan tanaman sehingga dapat memberikan hasil yang produksi yang maksimal. Penambahan arang sekam dan pupuk kandang sapi sebagai kombinasi media tanam dapat memperbaiki struktur media tanam, memiliki kandungan unsur hara yang mencukupi, dan kemampuan porositas yang baik sehingga kelembapan media tanam tetap terjaga.

Menurut Juniyati, et al. (2016) kombinasi media tanam tanah, arang sekam, dan pupuk kandang berpengaruh nyata terhadap pertumbuhan dan hasil produksi tanaman. Di sisi lain petani di
Indonesia masih bergantung pada pupuk kimia yang apabila digunakan secara terus menerus akan berdampak tidak baik pada lingkungan terutama pada lahan pertanian. Penggunaan pupuk kimia secara berkelanjutan dapat merusak tekstur tanah, membunuh mikroorganime yang ada di dalam tanah, mempengaruhi $\mathrm{pH}$ tanah, mencemari perairan atau sungai, dan berdampak buruk bagi kesehatan manusia yang mengonsumsi hasil pertanian tersebut (Andriyani, et al., 2020).

Trichoderma sp. merupakan jamur yang bersifat parasit terhadap jamur lain dan dikenal luas sebagai pupuk biologi tanah. Jamur ini dapat berperan sebagai biodekomposer. Trichoderma sp. memberikan pengaruh positif terhadap perakaran tanaman, pertumbuhan tanaman dan hasil produksi tanaman. Mekanisme kerjanya dengan menginfeksi akar sehingga akar yang terinfeksi akan tumbuh lebih banyak dibandingkan yang tidak terinfeksi. Perakaran yang banyak menyebabkan penyerapan unsur hara lebih optimum, sehingga tanaman dapat tumbuh dengan baik (Arsensi, 2014). 
Penggunaan Trichoderma sp. diharapkan dapat mengurangi ketergantungan dan mengatasi dampak negatif dari pemakaian pupuk kimia. Selain itu, Trichoderma sp. cair juga mampu meningkatkan pertumbuhan dan produksi tanaman sehingga didapatkan hasil produksi yang optimal. Menurut Arsensi (2014), pemberian Trichoderma sp. cair sebanyak $10 \mathrm{ml}$ per tanaman berpengaruh nyata terhadap pertumbuhan dan hasil produksi tanaman cabai. Penelitian ini dilaksanakan bertujuan untuk mengetahui komposisi media dan dosis Trichoderma sp. cair yang tepat agar pertumbuhan dan hasil produksi tanaman cabai rawit maksimal.

\section{METODE PENELITIAN}

Penelitian dilaksanakan di Kelurahan Sukorejo, Kecamatan Sutojayan, Kabupaten Blitar. Lokasi penelitian berada pada ketinggian $180 \mathrm{~m}$ dpl dengan curah hujan 2.268 $\mathrm{mm}^{2}$ per tahun dengan suhu harian 23-15 ${ }^{\circ} \mathrm{C}$. Penelitian dilaksanakan pada bulan Februari-Mei 2021. Bahan yang digunakan adalah benih cabai rawit, Trichoderma $s p$. cair, media tanam (tanah, arang sekam, pupuk kandang), babybag, dan polybag.

Penelitian ini menggunakan Rancangan Acak Kelompok (RAK) yang disusun secara faktorial terdiri dari 2 faktor yang masing-masing terdiri dari tiga perlakuan yang diulang 3 kali. Faktor 1 adalah media tanam yang terdiri dari tanah $\mathrm{M} 1=$ tanah : $\operatorname{arang} \operatorname{sekam}(1: 1) ; \mathrm{M} 2=$ tanah : arang sekam : pupuk kandang (1:1:1); dan M3. Faktor 2 adalah dosis Trichoderma sp.cair yang terdiri dari $\mathrm{T} 1=$ Trichoderma sp. cair 5 ml/tanaman, $\mathrm{T} 2=$ Trichoderma $\quad s p . \quad$ cair 10 ml/tanaman, dan T3=Trichoderma sp. cair $15 \mathrm{ml} /$ tanaman. Trichoderma $s p$. yang digunakan merupakan Trichoderma sp. cair dengan kerapatan spora $135 \times 10^{8}$ per liter yang dilarutkan dengan konsentrasi $4 \mathrm{ml} /$ liter untuk semua perlakuan. Pemberian Trichoderma $s p$. cair pada tanaman cabai dilakukan 10 hari setelah tanam, kemudian setiap 10 hari sekali sebanyak 3 kali yaitu pada umur 10 HST, 20 HST, dan 30 HST dengan cara menambahkan Trichoderma sp. cair sesuai dengan konsentrasi masing-masing perlakuan yaitu dan disiramkan ke 
media tanam sekitar perakaran.

Parameter yang diamati meliputi tinggi tanaman $(\mathrm{cm})$ dan diameter batang $(\mathrm{cm})$ yang diamati saat tanaman cabai berumur 14,28 , 42, 56, 70 HST. Total jumlah buah per tanaman dan total bobot buah segar per tanaman diamati saat tanaman berumur 75 HST dalam 5 kali panen, yaitu pada umur 75,80 , 85, 90 dan 100 HST.

Data yang diperoleh dianalisis ragam (uji F) pada taraf 5\%. Bila hasil pengujian menunjukkan pengaruh yang nyata, maka dilanjutkan dengan uji perbandingan antar perlakuan menggunakan uji Duncan pada taraf 5\%.

\section{HASIL DAN PEMBAHASAN}

\section{Tinggi Tanaman}

Hasil analisis dari sidik ragam menunjukkan bahwa terdapat interaksi yang nyata pada tinggi tanaman cabai rawit pada umur pengamatan $14 \mathrm{HST}, 28 \mathrm{HST}, 42$ HST, 56 HST dan 70 HST. Kombinasi perlakuan media tanam dan pemberian Trichoderma sp. cair $10 \mathrm{ml}$ (M3T2) menghasilkan tinggi tanaman terbaik (Tabel 1).

Tabel 1. Tinggi Tanaman Cabai Rawit pada Umur 14 HST, 28 HST, 42 HST, 56 HST, dan 70 HST

\begin{tabular}{|c|c|c|c|c|c|c|c|c|c|}
\hline \multirow[b]{2}{*}{ Perlakuan } & \multirow[b]{2}{*}{14} & \multicolumn{7}{|c|}{ Tinggi Tanaman $(\mathrm{cm})$} & \\
\hline & & 28 & & 42 & & 56 & & 70 & \\
\hline & HST & HST & & HST & & HST & & HST & \\
\hline M1T1 & $7,50 \mathrm{a}$ & 16,71 & $\mathrm{a}$ & 28,67 & $\mathrm{a}$ & 38,47 & $\mathrm{a}$ & 40,49 & $\mathrm{a}$ \\
\hline M1T2 & $7,83 \mathrm{~b}$ & 17,50 & $\mathrm{a}$ & 30,13 & $\mathrm{~b}$ & 39,80 & $\mathrm{~b}$ & 43,64 & $\mathrm{c}$ \\
\hline M1T3 & 7,61 a & 17,16 & $\mathrm{a}$ & 29,30 & $a b$ & 39,02 & $\mathrm{a}$ & 42,21 & $\mathrm{~b}$ \\
\hline M2T1 & $8,06 \mathrm{c}$ & 23,91 & $\mathrm{~b}$ & 37,17 & $\mathrm{c}$ & 47,42 & $\mathrm{c}$ & 51,67 & d \\
\hline M2T2 & $8,50 \mathrm{f}$ & 26,43 & $\mathrm{c}$ & 39,04 & $\mathrm{~d}$ & 48,83 & $\mathrm{~d}$ & 54,88 & $\mathrm{f}$ \\
\hline M2T3 & $8,28 \mathrm{~d}$ & 24,56 & $\mathrm{~b}$ & 37,98 & $\mathrm{~cd}$ & 48,18 & $\mathrm{~cd}$ & 52,87 & $\mathrm{e}$ \\
\hline M3T1 & $8,75 \mathrm{~g}$ & 32,60 & $\mathrm{~d}$ & 47,51 & $\mathrm{e}$ & 57,66 & $\mathrm{e}$ & 60,31 & $\mathrm{~g}$ \\
\hline M3T2 & $9,50 \mathrm{~h}$ & 38,00 & $\mathrm{e}$ & 52,13 & $\mathrm{f}$ & 60,62 & $\mathrm{~g}$ & 65,00 & $\mathrm{i}$ \\
\hline M3T3 & $8,89 \mathrm{~g}$ & 33,29 & $\mathrm{~d}$ & 47,96 & $\mathrm{e}$ & 58,48 & $\mathrm{f}$ & 61,4 & $\mathrm{~h}$ \\
\hline
\end{tabular}

Keterangan: angka-angka yang diikuti dengan huruf yang sama pada kolom yang sama tidak berbeda nyata pada uji Duncan $(\alpha=0,05)$ 
Kombinasi perlakuan media tanam tanah, arang sekam, dan pupuk kandang dengan penambahan Trichoderma $s p$. cair memberikan hasil pertumbuhan tanaman lebih maksimal. Komposisi media tanam yang ditambahkan arang sekam diduga memiliki kemampuan menahan air yang tinggi menjaga ketersediaan air pada media tanam agar tetap tercukupi bagi tanaman cabai dan membuat media tanam memiliki porositas yang baik sehingga kelembaban media tanam tetap terjaga serta memperbaikan struktur media tanam sehingga sesuai sebagai tempat hidup tanaman. Kondisi media tanam sesuai dan kadar air tercukupi untuk tanaman membuat pertumbuhan tanaman maksimal terutama pada pertumbuhan tinggi tanaman. Hal tersebut didukung dengan pendapat Septiani (2012) dalam Juniyati, et al. (2016) bahwa arang sekam memiliki kemampuan menahan air yang tinggi dan porositas yang baik sehingga dapat mendukung perbaikan struktur tanah karena aerasi dan drainase menjadi lebih baik. Arang sekam juga mengandung unsur hara $\mathrm{C}, \mathrm{N}$, $\mathrm{P}, \mathrm{K}, \mathrm{Ca}$, dan $\mathrm{Mg}$ yang berfungsi sebagai nutrisi sehingga pertumbuhan tanaman menjadi maksimal. Hal ini didukung oleh Nasrulloh, et al. (2016) yang menyatakan bahwa arang sekam memiliki kandungan unsur hara penting seperti nitrogen $(\mathrm{N})$, fosfor (P), kalium (K), kalsium (Ca) dan Magnesium (Mg). Media tanam sekam kompos banyak membawa keuntungan yaitu mengandung karbon (C) yang membuat media tanam menjadi gembur. Hal ini membantu merangsang pertumbuhan secara keseluruhan khususnya batang, cabang, dan daun serta zat hijau daun untuk fotosintesis dan memiliki unsur fosfor, kalium. Kondisi media tanam yang baik akan mendorong perakaran tanaman tumbuh secara optimal dengan demikian akan meningkatkan ketersedian unsur nitrogen, fosfor, dan kalium (Anggarini dan Widowati, 2017).

Komposisi media tanam tanah, arang sekam, dan pupuk kandang yang memiliki kandungan $\mathrm{C}$ dan $\mathrm{N}$ dapat menjadi asupan nutrisi bagi Trichoderma $s p$. serta media tanam yang memiliki kelembaban tinggi diduga menjadi tempat yang sesuai bagi Trichoderma sp. untuk hidup dan berkembangbiak. Trichoderma 
$s p$. yang diaplikasikan ke tanah daerah perakaran akan langsung dapat tumbuh dan berkembangbiak dalam waktu 3 - 4 hari dan akan menginfeksi permukaan akar atau korteks menyebabkan selnya berpoliferasi sehingga jumlah sel di dalam akar meningkat. Akar yang terinfeksi Trichoderma sp. akan membentuk cabang akar yang lebih banyak sehingga penyerapan unsur hara menjadi lebih baik dan hasil penyerapan unsur hara akan diedarkan ke seluruh organ tanaman yang akan digunakan untuk proses fisiologi maupun pertumbuhan tanaman. Hal ini didukung oleh Suwanda (2018) yang menyatakan nutrisi yang diperlukan Trichoderma $s p$. antara lain adalah sumber karbon, nitrogen dan air. Kelembaban yang tinggi merupakan tempat yang sesuai untuk hidup dan berkembangbiak. Akar yang terinfeksi Trichoderma $s p$. akan membentuk akar-akar cabang yang lebih banyak dibandingkan dengan akar yang tidak terinfeksi. Perakaran yang banyak tersebut dapat membantu penyerapan unsur hara menjadi lebih baik, sehingga tanaman dapat tumbuh dengan baik. Dengan kebutuhan hara yang cukup maka proses fisiologi pada tanaman akan berlangsung dengan baik. Hasil penyerapan unsur hara akan diedarkan ke seluruh organ tanaman yang akan digunakan untuk proses fisiologi maupun pertumbuhan tanaman (Wayan, 2016).

\section{Diamater Batang}

Hasil analisis dari sidik ragam menunjukkan bahwa terdapat interaksi yang nyata pada diameter batang tanaman cabai rawit pada umur pengamatan $14 \mathrm{HST}$, $28 \mathrm{HST}$, 42 HST, 56 HST, dan 70 HST. Perlakuan media tanam tanah, arang sekam, pupuk kandang dan pemberian Trichoderma sp. cair 10 ml (M3T2) menghasilkan diameter batang tanaman terbesar (Tabel 2). 
Tabel 2. Rata-rata Diameter Batang Tanaman Cabai Rawit pada Umur Pengamatan 14 HST, 28 HST, 42 HST, 56 HST, dan 70 HST

\begin{tabular}{|c|c|c|c|c|c|c|c|c|c|c|}
\hline \multirow{3}{*}{ Perlakuan } & \multicolumn{10}{|c|}{ Diameter Batang $(\mathrm{cm})$} \\
\hline & 14 & & 28 & & 42 & & 56 & & 70 & \\
\hline & HST & & HST & & HST & & HST & & HST & \\
\hline M1T1 & 0,16 & $\mathrm{a}$ & 0,21 & $\mathrm{a}$ & 0,39 & $\mathrm{a}$ & 0,41 & $\mathrm{a}$ & 0,43 & $\mathrm{a}$ \\
\hline M1T2 & 0,18 & $\mathrm{a}$ & 0,23 & $\mathrm{a}$ & 0,45 & $\mathrm{~b}$ & 0,47 & $\mathrm{~b}$ & 0,51 & $\mathrm{~b}$ \\
\hline M1T3 & 0,17 & $\mathrm{a}$ & 0,23 & $\mathrm{a}$ & 0,41 & a & 0,42 & $\mathrm{a}$ & 0,45 & $\mathrm{a}$ \\
\hline M2T1 & 0,22 & $\mathrm{~b}$ & 0,29 & $\mathrm{~b}$ & 0,47 & $\mathrm{bc}$ & 0,61 & $\mathrm{c}$ & 0,72 & $\mathrm{c}$ \\
\hline M2T2 & 0,24 & $\mathrm{bc}$ & 0,32 & $\mathrm{~b}$ & 0,51 & $\mathrm{c}$ & 0,69 & d & 0,79 & $\mathrm{~d}$ \\
\hline M2T3 & 0,23 & bc & 0,31 & $\mathrm{~b}$ & 0,49 & $\mathrm{bc}$ & 0,63 & $\mathrm{c}$ & 0,75 & $\mathrm{~cd}$ \\
\hline M3T1 & 0,25 & $\mathrm{c}$ & 0,38 & $\mathrm{c}$ & 0,61 & $d$ & 0,72 & d & 0,88 & $\mathrm{e}$ \\
\hline M3T2 & 0,31 & $\mathrm{~d}$ & 0,42 & $\mathrm{c}$ & 0,64 & $\mathrm{~d}$ & 0,83 & $\mathrm{f}$ & 1,08 & $\mathrm{~g}$ \\
\hline M3T3 & 0,26 & $\mathrm{c}$ & 0,38 & $\mathrm{c}$ & 0,62 & $d$ & 0,79 & e & 0,97 & $\mathrm{f}$ \\
\hline
\end{tabular}

Keterangan: angka angka yang diikuti dengan huruf yang sama pada kolom yang sama tidak berbeda nyata pada uji Duncan $(\alpha=0,05)$

Kombinasi perlakuan media tanam tanah, arang sekam, dan pupuk kandang dengan penambahan Trichoderma sp. cair memberikan hasil pertumbuhan tanaman lebih baik. Penambahan pupuk kandang sapi sebagai komposisi media tanam diduga dapat mendukung pertumbuhan tanaman menjadi lebih baik dari awal pertumbuhan dan berpengaruh terhadap diameter batang tanaman cabai. Hal ini dikarenakan pupuk kandang sapi yang ditambahkan dapat menambah unsur hara $\mathrm{N}$ ke dalam tanah karena adanya mikroorganisme yang dapat mengubah bahan organik menjadi unsur hara yang dapat dimanfaatkan oleh tanaman. Penambahan pupuk kandang sapi juga dapat memperbaiki stuktur tanah karena di dalam pupuk kandang sapi terdapat mikroorganisme yang dapat menguraikan bahan organik dan aktivitas mikroorganisme di dalam tanah dapat membuat pori di dalam media tanam sehingga membuat penyerapan air dan pergerakan udara di dalam media tanam (aerasi) menjadi lebih baik. Hal ini didukung oleh pendapat dari Polta dan Subagiono (2018) yang 
menyatakan pupuk kandang sapi yang dijadikan media tanaman mengandung unsur hara terutama unsur nitrogen yang relatif rendah $(0,51 \%)$, tetapi memiliki manfaat yang besar dalam memperbaiki aerasi, struktur, dan kelembapan tanah, sehingga pertumbuhan dan perkembangan akar tanaman menjadi baik, serta memperluas jangkauan akar tanaman sehingga jangkauan tanaman untuk menyerap unsur hara dan air lebih maksimal.

$$
\text { Media tanam yang }
$$

mengandung nutrisi $\mathrm{N}$ dan memiliki kelembapan yang tinggi menjadi tempat yang sesuai bagi Trichoderma sp. Trichoderma sp. yang diaplikasikan ke dalam tanah akan menginfeksi perakaran tanaman berfungsi untuk memecah bahan-bahan organik yang ada di dalam media tanam menguraikan bahan organik di dalam tanah yang mempermudah tanaman dalam menyerap unsur hara $\mathrm{N}, \mathrm{P}, \mathrm{S}$ dan $\mathrm{Mg}$ sehingga dapat tersedia dan diserap oleh tanaman dan mempengaruhi pertumbuhan tanaman terutama pada diameter batang. Hal tersebut sesuai dengan penelitian Rizal (2018) yang menyatakan bahwa Trichoderma $s p$. berfungsi untuk memecah bahanbahan organik. Keberadaan Trichoderma sp. didalam tanah mempengaruhi serapan unsur hara tanaman utamanya N, karena Trichoderma sp. mampu menguraikan bahan organik di dalam tanah yang mempermudah tanaman dalam menyerap unsur hara tersebut seperti $\mathrm{N}, \mathrm{P}, \mathrm{S}$ dan $\mathrm{Mg}$ (Marianah, 2013 dalam Rizal, 2018).

\section{Total Jumlah Buah dan Bobot Buah Per Tanaman}

Hasil analisis dari sidik ragam menunjukkan bahwa terdapat interaksi perlakuan yang nyata pada total jumlah buah tanaman cabai rawit. Kombinasi perlakuan media tanam dan pemberian Trichoderma sp. cair $10 \mathrm{ml}$ (M3T2) menghasilkan jumlah buah cabai rawit terbanyak (Tabel 3). 
Tabel 3. Total Jumlah Buah dan Bobot Buah Cabai Rawit Per Tanaman

\begin{tabular}{|c|c|c|}
\hline Perlakuan & Jumlah Buah Per Tanaman & Bobot BuahPer Tanaman \\
\hline M1T1 & $34,99 \mathrm{a}$ & $36,32 \mathrm{a}$ \\
\hline M1T2 & $44,33 \mathrm{c}$ & $46,99 \mathrm{c}$ \\
\hline M1T3 & $38,33 \mathrm{~b}$ & $39,33 \mathrm{~b}$ \\
\hline M2T1 & $56,67 \mathrm{~d}$ & $57,00 \mathrm{~d}$ \\
\hline M2T2 & $69,67 \mathrm{f}$ & $72,63 \mathrm{f}$ \\
\hline M2T3 & $63,67 \mathrm{e}$ & $67,67 \mathrm{e}$ \\
\hline M3T1 & $81,35 \mathrm{~g}$ & $84,00 \mathrm{~g}$ \\
\hline M3T2 & $98,98 \mathrm{i}$ & $104,31 \mathrm{i}$ \\
\hline M3T3 & $84,67 \mathrm{~h}$ & $88,00 \mathrm{~h}$ \\
\hline
\end{tabular}

Keterangan: angka-angka yang diikuti dengan huruf yang sama pada kolom yang sama tidak berbeda nyata pada uji Duncan $(\alpha=0,05)$.

Kombinasi perlakuan media tanam tanah, arang sekam, dan pupuk kandang dengan penambahan Trichoderma sp. cair memberikan hasil pertumbuhan tanaman lebih maksimal dan hasil produksi tanaman cabai juga maksimal. Komposisi media tanam tanah, arang sekam, dan pupuk kandang yang ditambahkan dengan pemberian Trichoderma sp. cair memberikan hasil pertumbuhan pada tanaman cabai rawit lebih maksimal sehingga mendukung pertumbuhan generatif menjadi lebih maksimal terutama pada jumlah buah. Penambahan pupuk kandang sapi yang dikombinasikan dengan tanah dan arang sekam sebagai media tanam dapat mendukung perkembangan tanaman pada masa pembuahan sehingga hasil panen menjadi optimal. Hal ini dikarenakan pupuk kandang sapi yang ditambahkan dapat menambah unsur hara $\mathrm{N}, \mathrm{P}$, dan $\mathrm{K}$ ke dalam tanah yang dapat diserap oleh tanaman. Hal ini didukung oleh pendapat dari Polta dan Subagiono (2018) jenis pupuk kandang sapi mempunyai kadar serat yang tinggi seperti selulosa. Selain itu, pupuk ini juga mengandung unsur hara makro seperti $0,5 \mathrm{~N}, \quad 0,25 \quad \mathrm{P}_{2} \mathrm{O}_{5}$, 
$0,5 \% \mathrm{~K}_{2} \mathrm{O}$ dengan kadar air 0,5\%, dan juga mengandung unsur mikro esensial lainnya. Kandungan unsur hara $\mathrm{N}, \mathrm{P}$ dan $\mathrm{K}$ yang terkandung pada pupuk kandang sapi dapat diserap oleh perakaran tanaman secara maksimal apabila ditambahkan dengan Trichoderma $s p$. cair sebanyak $10 \mathrm{ml}$ per tanaman.

Hasil analisis dari sidik ragam menunjukkan bahwa terdapat interaksi yang nyata pada total bobot buah tanaman cabai rawit. Kombinasi perlakuan media tanam dan pemberian Trichoderma sp. cair $10 \mathrm{ml}$ (M3T2) menghasilkan total bobot buah tanaman cabai rawit terbaik (Tabel 3).

Hanudin, et al. (2018) menyatakan bahwa mekanisme kerja Trichoderma sp. dalam mempengaruhi pertumbuhan tanaman dengan cara menginduksi pertumbuhan tanaman melalui perubahan komunitas mikroba pada perakaran (rhizosfer) untuk memproduksi berbagai macam senyawa organik. Trichoderma $s p$. dapat mempengaruhi pertumbuhan tanaman secara langsung melalui kemampuannya meningkatkan ketersediaan nutrisi bagi tanaman.
Pemberian larutan Trichoderma sp. $15 \mathrm{ml}$ menghambat pertumbuhan karena semakin banyak populasi Trichoderma sp. dalam satu polybag maka akan terjadi kompetisi antara Tricoderma $s p$. dengan tanaman cabai dalam penyerapan unsur hara karena Trichoderma sp. juga memerlukan unsur hara sebagai asupan nutrisi. Karena populasinya yang tinggi menyebabkan hara yang seharusnya digunakan optimal oleh tanaman, digunakan sebagian oleh Trichoderma sp. dalam tanah (Rizal, 2018).

\section{KESIMPULAN DAN SARAN \\ Kesimpulan}

Terdapat interaksi yang sangat nyata pada kombinasi media tanam dengan dosis Trichoderma sp. cair. Kombinasi terbaik yaitu perlakuan media tanam tanah : arang sekam : pupuk kandang (1:1:1) yang ditambahkan larutan Trichoderma $s p$. cair $10 \mathrm{ml}$ (M3T2) pada variabel tinggi tanaman dan diameter batang pada umur 14, 28, 42, 56, 70 HST, dan total jumlah buah pertanaman sebesar 98,98 buah dan total bobot buah peranaman sebesar 104,31 gram. 


\section{Saran}

Perlu dikembangkan penelitian mengenai kombinasi media tanam lain yang dapat meningkatkan pertumbuhan dan hasil produksi tanaman cabai dan penelitian dengan dosis dosis Trichoderma $s p$. cair yang lebih tinggi dari $15 \mathrm{ml}$ per tanaman.

\section{DAFTAR PUSTAKA}

Ajak Agustinus., I.C.O. Roberto dan Taolin. 2016. Pengaruh Olah Tanah dan Jenis Pupuk Kandang Terhadap Pertumbuhan dan Hasil Cabai Rawit Varietas Bara (Capsicum frutescens L). Jurnal Pertanian Konservasi Lahan Kering.1(3): 98-101.

Arsensi, I. 2014. Respon Tanaman Cabai Merah Varietas Prabu Terhadap Penggunaan Trichoderma sp. dalam Mengendalikan Penyakit Layu Fusarium. Jurnal Dinamika Pertanian. XXIX (2).

Andriyani D. H., C.P. Juliansyah, S. Melita. 2020. Peningkatan Produktivitas Lahan dan Pendapatan Petani melalui Penggunaan Pupuk Organik Di Desa Blang Gurah Kecamatan Kutai Makmur kabupaten Aceh Utara. Jurnal Ekonomi Pertanian Unimal. 03 (02).

Anggraini, D dan H. Widowati. 2013. Perbandingan Produksi Cabai Merah (Capsicum annum L) Antara yang Menggunakan Media Tanam Sekam bakar Kompos dengan Sekam Bakar Pupuk Kandang Sebagai Sumber Belajar Biologi SMA. J Bioedukasi UM Metro. 4 (2).

Hanudin, K. Budiarto, B. Marwoto. 2018. Potensi Beberapa Mikroba Pemacu Pertumbuhan Tanaman Sebagai Bahan Aktif Pupuk dan Pestisida Hayati. J. Litbang Pertanian. 37 (2).

Juniyati, T, A. Adam, P. Patang. 2016. Pengaruh Komposisi Media Tanam Organik Arang Sekam dan Pupuk Padat Kotoran Sapi dengan Tanah Timbunan terhadap Pertumbuhan dan Kelangsungan Hidup Tanaman Kangkung Darat (Ipomoea reptans Poir). Jurnal Pendidikan Teknologi Pertanian. 2: 9-15.

Kusumawati R. D., D. Hariyono , dan N. Aini. 2016. Pengaruh Komposisi Media Tanam dan Interval Pemberian Air Sampai dengan Kapasitas Lapang Terhadap Produksi Tanaman Cabai Rawit (Capsicum frutescens L.). Journal of Agricultural Science. 1(2): 6471.

Polta A.K dan Subagiono. 2018. Pengaruh Pemberian Beberapa Jenis Pupuk Kandang Terhadap Pertumbuhan Bibit Kopo Varietas Robusta (Coffea robusta). J. Sains Agro. 03(02). 
Rizal, S., D. Novianti dan M. Septiani. 2019. Pengaruh Jamur Trichoderma $s p$ Terhadap Pertumbuhan Tanaman Tomat (Solanum lycopersicum L). Jurnal Indobiosains. 1 (1).

Suwanda, I. W. 2018. Pengaruh Pupuk Trichoderma sp. dengan Media Tumbuh Berbeda terhadap Pertumbuhan Vegetatif Tanaman Cabai Rawit (Capsicum frutescens L.). Widya Biologi. 1(1).

Wiraatmaja, I.W. 2016. Pergerakan Hara Mineral dalam Tanaman. https://simdos.unud.ac.id/uplo ads/file_pendidikan_1_dir/cab 302690a210a3fcb6f8f38e4f68 a20.pdf. 